\title{
Study of Recording Performances for Co-Ni-Mn Spinel Fine-Particle Media
}

\author{
H. Nishio and H. Yamamoto \\ School of Science and Technology, Meiji University, 1-1-1 Higashimita, Tama-ku, Kawasaki 214-8571, Japan
}

\begin{abstract}
A flexible disk medium composed of $\mathrm{Co}-\mathrm{Ni}-\mathrm{Mn}$ spinel ferrite fine particles was investigated in order to confirm its high-density recording performance. This medium was prepared from particles with a mean size of $25 \mathrm{~nm}$ using a spin coater without burnishing. The average surface roughness and particle size of the coated disk were approximately 20 and $34 \mathrm{~nm}$, respectively. The recording characteristics were measured on a spinstand tester at a rotating speed of $2940 \mathrm{rpm}$, using a floating MIG head for writing and reading. The linear recording density at $50 \%$ of maximum output was $52 \mathrm{kBPI}$, whereas that of commercial zip media (Fe-Co particles) was $67 \mathrm{kBPI}$. The overwrite performance is very important for high-density recording, and it was better than $28 \mathrm{~dB}$, which was close to the results for zip media at $1 \mathrm{MHz}$. The carrier-to-noise ratio for this disk was $32.2 \mathrm{~dB}$ after writing a $10 \mathrm{MHz}$ signal, while the signal-to-noise ratio was $20.2 \mathrm{~dB}$ with the band width of $50 \mathrm{MHz}$, after writing a $20 \mathrm{MHz}$ signal. The results of experiments showed that the $\mathrm{Co}-\mathrm{Ni}-\mathrm{Mn}$ spinel ferrite disk has potential for use in high-density data storage tapes.
\end{abstract}

Key words: Co-Ni-Mn spinel fine particles, data storage tape, linear recording density, overwrite, carrier-to-noise ratio

\section{$\mathrm{Co}-\mathrm{Ni}-\mathrm{Mn}$ 系スピネル微粒子媒体の記録再生に関する検討}

西尾博明・山元 洋

明治大学理工学部, 神奈川県川崎市多摩区東三田 1-1-1 ( ₹ 214-8576)

\section{1.はじめに}

近年，高度情報化社会の到来により業務および民生分野 で扱うデータ量は急速に増加し, データ保存装置の大容量 化が強く求められている. 光れを主として担うハードディ スク装置のデータバックアップには, 媒体を自由に取り出 して安全な環境に長期間保存できる磁気テープ装置が適し ている. 磁気テープ装置にはヘリカルおよびリニア記録方 式があり，両者の面記録密度はほぼ同程度になっている. 弚れらに用いられる極薄磁気テープとしては蒸着法と塗布 法があり, 後者は生産効率が高く, ビデオ分野で長年の信 頼性を有し，両記録方式に対応できる利点がある ${ }^{1)}$.

保存データの高い信頼性が不可欠なデータバックアップ 用磁気テープには, さらなる高記録密度化に対する要求が 高まってきており, 磁気テープに用いる磁性粉の微細化お

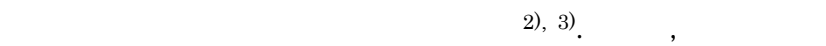
よるデータバックアップテープの製品に用いられている微 細な磁性粉には, 主として形状磁気異方性を利用した針状 のメタル(Fe-Co)があり, 球状でコア・シェル構造を有する $\mathrm{Sm}-\mathrm{FeCo}-\mathrm{B}$ および結晶磁気異方性を用いた六角板状の Ba 系フェライト微粒子などか開発に用いられている ${ }^{2)-7) . ~ し ~}$ かしながら，いずれの磁性粉も微細化に伴い，これらの保 磁力 $\left(H_{\mathrm{c}}\right)$ は約 200-240 kA/m (2.5-3.0 kOe)か限界である ことが知られている.

著者らは化学的共沈法による $\mathrm{Co}-\mathrm{Ni}-\mathrm{Mn}$ 系スピネルフェ ライト微粒子について一連の研究を継続しており, モル比 $\mathrm{n}\left\{=\mathrm{Fe}^{3+} /\left(\mathrm{Co}^{2+}+\mathrm{Ni}^{2+}+\mathrm{Mn}^{2+}\right)\right\}, \mathrm{Mn}$ 置換量および $\mathrm{pH}$ 等の作 製条件の最適化により高保磁力微粒子を得ている ${ }^{8)}$. デー タバックアップテープの記録再生の検討には, ドラムテス
タを用いることが多い，乥れには，表面の平坦性が優れた テープの作製が不可欠で，関連設備および技術が必須とな る. 乥こで本研究では, 最近のメタルおよび Ba 系フェラ イト微粒子よりも $H_{\mathrm{c}}$ が高い Co- $\mathrm{Ni}-\mathrm{Mn}$ スピネルフェライ 卜微粒子を用い, 記録再生の可能性を確認する初期段階と して, 比較的表面の平坦性が良い媒体が得られるスピンコ 一ト法でディスクを作製した (以後, Co- $\mathrm{Ni}-\mathrm{Mn}$ スピネルデ ィスクと略す) . まず, 走査型プローブ顕微鏡を用いて試作 ディスクの表面解析を行い, 次に記録再生の可能性を確認す るために zip 用ヘッドを用いたスピンスタンドで線記録密 度特性, オーバーライト特性および信号と杂隹音の比の概略 を市販の $100 \mathrm{MB}$ 用 zip 媒体と比較した.

\section{2. 実験方法}

2.1 スピネルフェライト微粒子を用いたディスクの作製 著者らの実験ては, Co-Ni-Mn スピネルフェライト微粒子 は $H_{\mathrm{c}}$ が大き過ぎて現用のシステムでは記録が不可能であ ると思われる ${ }^{8)}$ ，光こで，水酸化物のアルカリ添加比およ び生成量を制御した共沈法で $H_{\mathrm{c}}$ を抑えて作製された戶田 工業(妹製の微粒子をディスク作製に用いた ${ }^{9}$. 弚の分析組成 は $(\mathrm{CoO})_{0.54}(\mathrm{NiO})_{0.38}(\mathrm{MnO})_{0.08} \square 1.03\left(\mathrm{Fe}_{2} \mathrm{O}_{3}\right)$ であった. 微粒子の結 晶構造を調べるために X 線回折を行った結果, スピネル単相であ ることを磪忍した。微粒子の比表面積 $(S S A)$ は $54.7 \times 10^{3} \mathrm{~m}^{2} / \mathrm{kg}$, 透過型電子顕版鏡(TEM) て観察した平均粒子直径は約 $25 \mathrm{~nm}$ であ つた. 最大磁界 $1.57 \mathrm{MA} / \mathrm{m}$ (19.7 kOe)の振重场式料型磁力計(VSM) で測定した磁気特性は, 飽和磁化 $\sigma_{\mathrm{s}}=83.6 \mathrm{~Wb} \cdot \mathrm{m} / \mathrm{kg}(66.5 \mathrm{emu} / \mathrm{g})$, 角型比 $S Q=0.636, H_{c}=245 \mathrm{kA} / \mathrm{m}(3.08 \mathrm{kOe})$ であった.

次に, 塩化ビニル酩夋ビニル共重合体, シクロヘキサン, トル エン, メチルエチルケトンを重量比 $1: 6.21: 6.21: 2.59$ の割哈で 
混合し，ラッカーを作製した ${ }^{10)}$. Co- $\mathrm{Ni}-\mathrm{Mn}$ スピネルフェライ 卜微粒子, ラッカー, 直径 0.3-0.4 mm のガラスビーズの重量比 が1:4:8となるように秤量し，ミキサーミルを用いて 8 時間分散 して磁性塗料を作製した ${ }^{10}$. スピンコータを用いて外径 93 $\mathrm{mm}$, 内径 $25 \mathrm{~mm}$, 厚さ約 $50 \mu \mathrm{m}$ のPET フィルムを 6000 $\mathrm{rpm}$ で回転させ, 产の上に磁性塗料を塗布した. 谷の後, $120{ }^{\circ} \mathrm{C}$ の恒温槽中で 1 時間キュアー処理を行い, 潤滑剂を スピンコートして記録再生の測定用ディスクとした．用い た潤滑剂SY-1 はフッソ系不活性液体で, 濃度 $0.025 \%$ に希 釈して使用した. なお，このディスクはカレンダー処理お よびバーニシュは行っていない. VSM で測定したCo-Ni-Mn スピネルディスクおよび比較用 zip 媒体の円周方向の残留 磁束密度 $B_{r}, S Q, H_{c}$ およひ飽和磁界 $\left(H_{\mathrm{s}}\right)$ を Table 1 に示す.

\section{2 記録再生特性の測定方法}

記録再生特性の測定には, ヘッドをトラックに対して横 切る方向に直進可動できるスピンスタンドを用いた. トラ ック幅 $6.4 \mu \mathrm{m}$, ギャップ長 $0.27 \mu \mathrm{m}$, コイル巻数 35 回 のヘッドを記録再生に用いた。 これは上面および下面用が 一組になっている浮上型 zip 用ヘッドで，一般に D-MIG (Double metal in gap) と呼ばれる誘導型である ${ }^{11}$. 測定デ イスクは zip 媒体用ジャケットに入れ, ジャケットの右方 に設置した高さ測定器のスクライバの下面で支えた. 左方 には zip 用へッドを置き, 乥の出力を記録再生用増幅器に 接続した. 最大電流 $50 \mathrm{~mA}$ (0 to peak)の記録用増幅器およ び帯域 $100 \mathrm{MHz}$, 利得 $50 \mathrm{~dB}$ の再生用増幅器を用いた. 記録信号の生成にはデータ・レートが $1.1 \mathrm{Gbps}$ のデータジ エネレータを, 再生スペクトルの解析には帯域幅 $1.5 \mathrm{GHz}$ のディジタルストレージオシロスコープおよび周波数の基 準確度が $7.5 \times 10^{-6}$ のスペクトラムアナライザを用いた.

媒体の記録再生特性の測定に先立ち，市販の $100 \mathrm{MB}$ 用

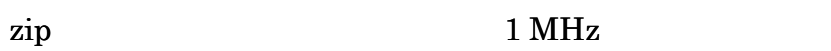
換算出力 $(T A A)$ とヘッド記録電流 $\left(I_{\mathrm{w}}\right)$ との関係を $I_{\mathrm{w}}=5-50$ $\mathrm{mA}$ の範囲で測定した結果, $I_{\mathrm{w}}=20 \mathrm{~mA}$ て飽和に達し, 弚の $T A A$ は $0.34 \mathrm{mV}$ であった. 次に $I_{\mathrm{w}}=20 \mathrm{~mA}$ における $T A A$ の記録信号周波数 $(f)$ 依存性を $0.1-20 \mathrm{MHz}$ において測定し たところ, TAA 值は約 $7 \mathrm{MHz}$ で半減することが分かった. zip 媒体に比へてて Hcが約 2 倍大きい Co-Ni-Mn スピネルデ イスクにおいても, 最適な $I_{\mathrm{w}}$ で記録再生特性を測定するこ とが望ましいと考えるが, 記録再生の可能性を確認する初 期段階として， $I_{\mathrm{w}}$ を上記の 2 倍の $40 \mathrm{~mA}$ として実験した.

ディスクの回転数は zip と同じ $2940 \mathrm{rpm}$ とした. 下面 用ヘッドを押えとして用い, 上面用記録再生ヘッドを垂直

Table 1 Magnetic properties of $\mathrm{Co}-\mathrm{Ni}-\mathrm{Mn}$ spinel ferrite and zip disks.

\begin{tabular}{|c|c|c|}
\hline & Co-Ni-Mn disk & zip disk \\
\hline$B_{\mathrm{r}}(\mathrm{T})$ & 0.10 & 0.30 \\
\hline$S Q$ & 0.73 & 0.63 \\
\hline$H_{\mathrm{c}}(\mathrm{kA} / \mathrm{m})$ & 270 & 126 \\
\hline$H_{\mathrm{s}}(\mathrm{MA} / \mathrm{m})$ & 1.10 & 0.24 \\
\hline
\end{tabular}

方向に上下させてディスク表面の直近までロードし, ディ スク中心からの距離 $r(\mathrm{~mm})$ を記録する. あらかじめ設定 した $f=1-20 \mathrm{MHz}, I_{\mathrm{w}}=40 \mathrm{~mA}$ を記録用増幅器から出力し, ディスクの一周に記録する. 次にヘッドを再生出力に切り 換え, 得られた再生用増幅器の出力波形を解析した.

\section{3. 実験結果}

\section{1 ディスクの表面観察}

高記録密度の達成には磁性粒子の微細化, 磁性層の均一 化, 平滑化およひ溥層化が重要である. Co-Ni-Mn スピネ ルディスクおよび zip 媒体の破断面を走査型電子顕微鏡 (SEM)で観察したところ, 磁性層の平均厚みは光れ約 0.7 および $0.2 \mu \mathrm{m}$ であった. ディスクの表面状態の観察には, 測長精度が優れた閉ループ方式の走査型プローブ顕微鏡 (SPM)を用いた. まず, 縦 $50 \mu \mathrm{m} \times$ 横 $50 \mu \mathrm{m}$ の範囲における 形状イメージを測定した. Co-Ni-Mn スピネルディスクの径方 向における表面粗さの一例を Fig. 1 に示す. このディスクの 算術平均粗さ $\left(R_{\mathrm{a}}\right)$ は約 $20 \mathrm{~nm}$, zip 媒体の $R_{\mathrm{a}}$ は約 $10 \mathrm{~nm}$ で あった ${ }^{12)}$. 次に, Co-Ni-Mn スピネルディスクの縦 $1.0 \mu \mathrm{m}$ $\times$ 横 $1.0 \mu \mathrm{m}$ の範囲における SPM 平面像を観察した後, 各々の粒界に輪郭線を引いて求めたイメージが Fig. 2 であ る. この図から $100 \mathrm{~nm}^{2}$ ごとの粒子断面積のヒストグラム を求め, Fig. 3 に示す. 粒子の平均断面積は約 $1140 \mathrm{~nm}^{2}$ で, 平均粒子径は約 $34 \mathrm{~nm}$ であった.

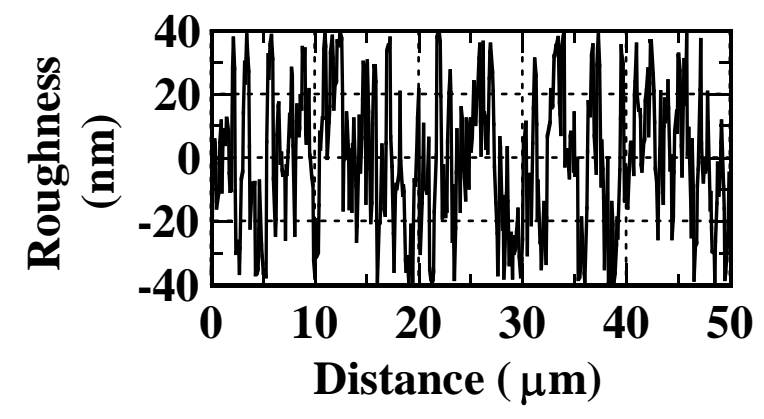

Fig. 1 Surface profile of a $\mathrm{Co}-\mathrm{Ni}-\mathrm{Mn}$ spinel ferrite disk.

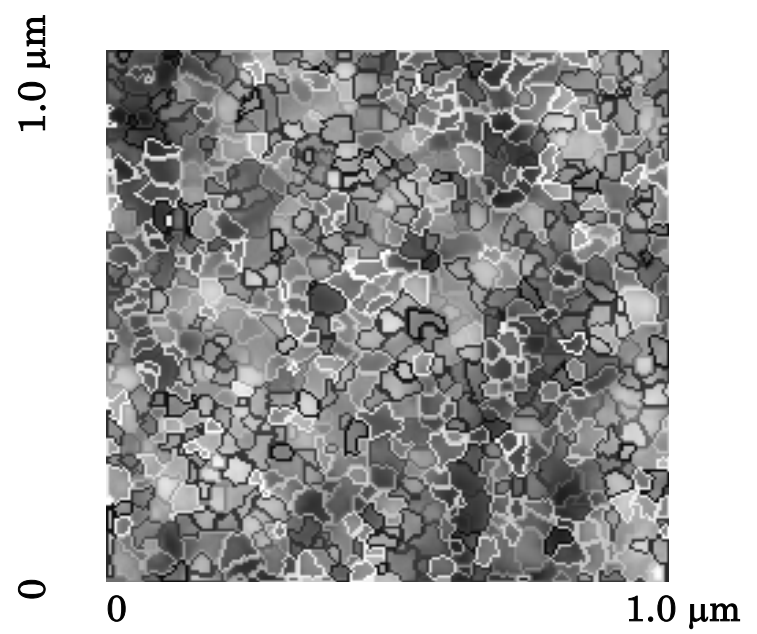

Fig. 2 Contour image obtained with a scanning probe microscope for a Co-Ni-Mn spinel ferrite disk. 


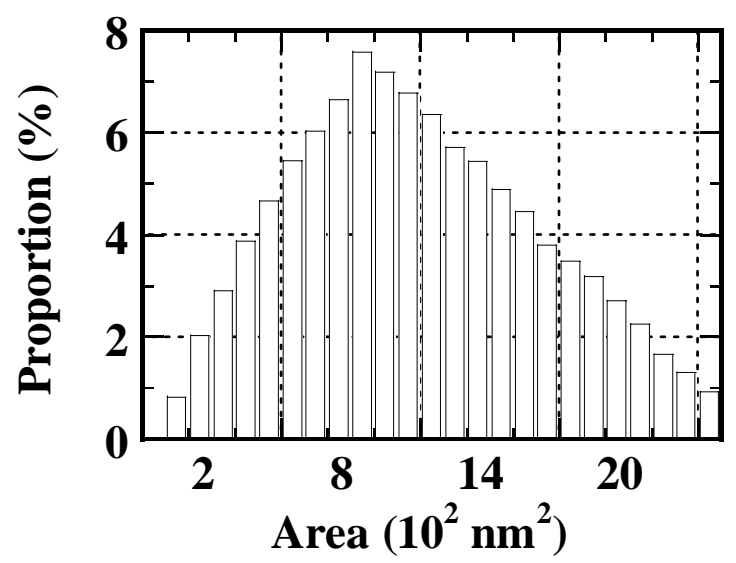

Fig. 3 Histogram of the particle area for a $\mathrm{Co}-\mathrm{Ni}-\mathrm{Mn}$ spinel ferrite disk.

\section{2 線記録密度特性}

Co-Ni-Mn スピネルディスクおよび比較用 zip 媒体に関 して, ディスク中心から半径 $r=32.6 \mathrm{~mm}$ (周速 $v=10040$ $\mathrm{mm} / \mathrm{s}$ に相当)の位置に $f=1-20 \mathrm{MHz}$ の信号を記録し, 光の 再生信号の一次成分を測定した. これらの周波数は線記録 密度に換算すると 5.06-101.2 kBPI に対応する. 得られた 線記録密度特性を Fig. 4 に示す. Co-Ni-Mn スピネルディ スクおよび比較用 zip 媒体の記録分解能を示す出力半減線 記録密度 $D_{50}$ は光れ攵れ約 52 および $67 \mathrm{kBPI}$ であった. 1 $\mathrm{MHz}$ で記録した場合の $1,3,5,7$ および $9 \mathrm{MHz}$ における 出力合計から求めた $\mathrm{Co}-\mathrm{Ni}-\mathrm{Mn}$ スピネルディスクおよび比 較用 zip 媒体のへッド換算出力は, 光れ光れ 55 および 342 $\mu \mathrm{V}_{\mathrm{p}-\mathrm{p}}$ であった. fが $20 \mathrm{MHz}$ 以内においては, Co- $\mathrm{Ni}-\mathrm{Mn}$ スピネルディスクの出力は zip 媒体に対して約 $12-24 \mathrm{~dB}$ 低 いが, 記録再生が可能であることが初めて明らかになった 市販の $100 \mathrm{MB}$ 用 zip 媒体に比べて, 自作した Co-Ni-Mn スピネルディスクの出力が低い主な理由として， $B_{x}$ が約 $1 / 3$ で小さいこと, $H_{\mathrm{c}}$ 約 2 倍で大きいことおよび $H_{\mathrm{s}}$ 滈いた めに zip ヘッドで十分に記録できない可能性があることな どか考えられる.

\section{3 オーバーライト特性}

ディジタル記録では, 方形波の記録信号電流により媒体 は正または負に飽和記録されるので，消去へッドを用いず に重ね書き (オーバーライト) がされている. 周波数 $f=1.0$ $\mathrm{MHz}, I_{\mathrm{w}}=40 \mathrm{~mA}$ で記録したときの出力 $(L F)$ を測定後, 同 じ電流值で 2 倍の周波数 $(2.0 \mathrm{MHz})$ で重ね書きをし, 元の $1.0 \mathrm{MHz}$ の消し残り出力電圧 $(R-L F)$ を測定し, 両者の出 力電圧の比を本実験ではオーバーライト特性とした.

$\mathrm{Co}-\mathrm{Ni}-\mathrm{Mn}$ スピネルディスクおよび比較用 zip 媒体の才 一バーライト特性を Fig. 5 および 6 に示す. Co-Ni-Mn ス ピネルディスクの $L F$ および $R-L F$ は光れ光れ-35.0 およ び-63.0 dBm で, オーバーライトは $28.0 \mathrm{~dB}$ と計算される. zip 媒体では, $L F$ および $R-L F$ は光れ光れ-22.2 および

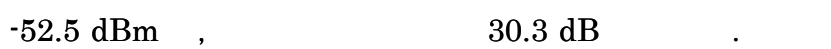
験では比較的記録周波が低く, また $L F$ と $R-L F$ の周波数

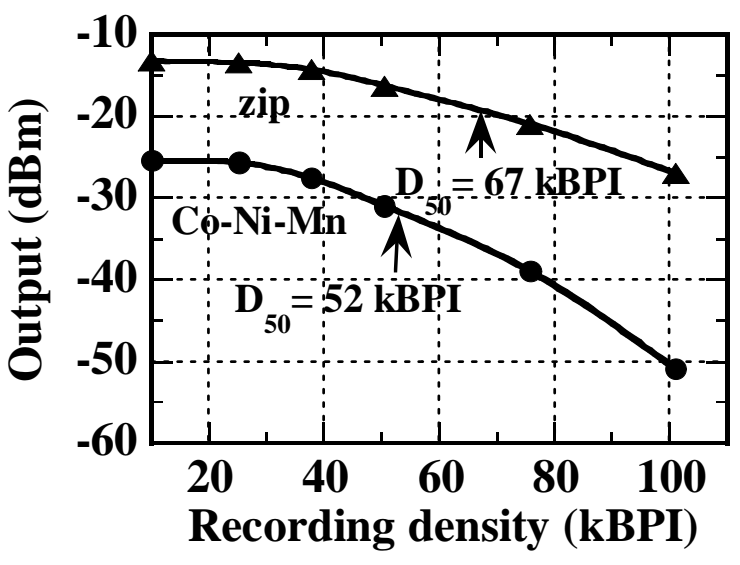

Fig. 4 Recording density dependence of the reproduced output for $\mathrm{Co}-\mathrm{Ni}-\mathrm{Mn}$ spinel ferrite and zip disks.

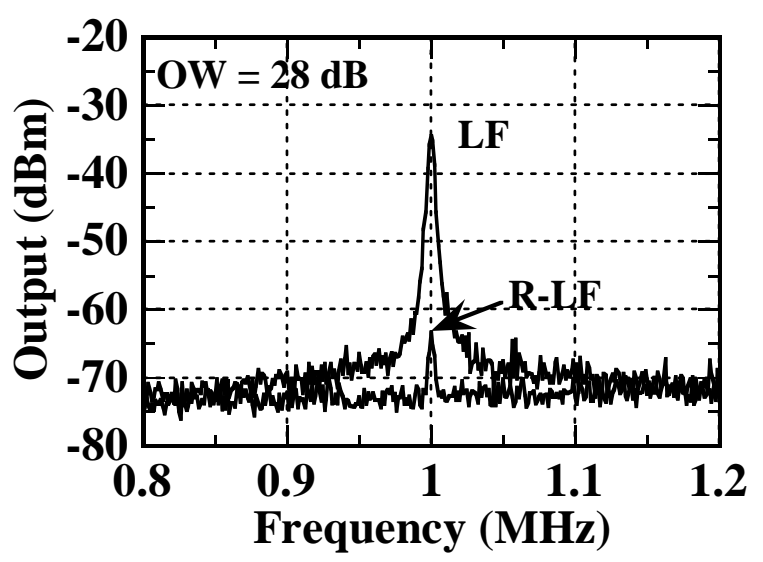

Fig. 5 Frequency spectra of overwrite for a $\mathrm{Co}-\mathrm{Ni}-\mathrm{Mn}$ spinel ferrite disk.

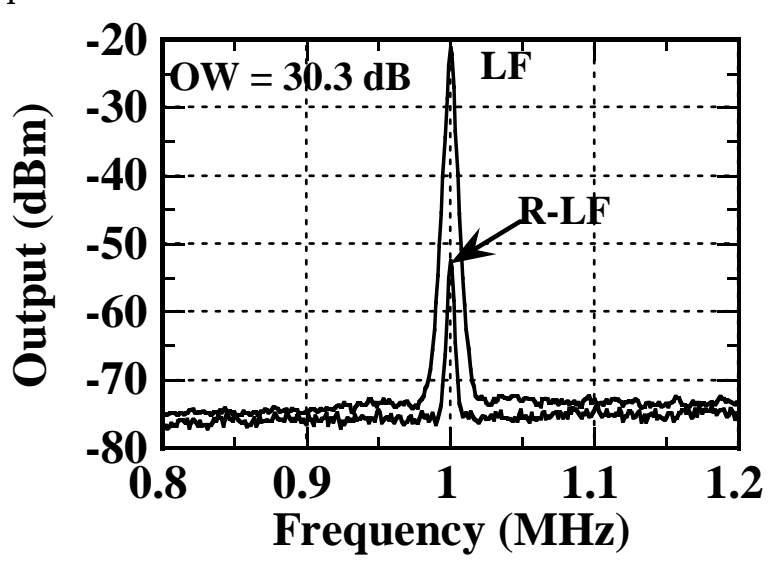

Fig. 6 Frequency spectra of overwrite for a zip disk.

の比が 2 倍と小さいために, 比較的良好なオーバーライト が得られたものと考えられる.

\section{4 信号と雑音の比}

次に, $f=5.0,7.5,10$ おび $20 \mathrm{MHz}$ で記録したときの信 号と杂隹音の比を測定した. Fig. 7 に $10 \mathrm{MHz}$ で記録したと きの信号および機器雑音スペクトルを示す. 単一周波数 $f$ の信号を記録し, これを再生した時の出力信号を关の周波 数における雑音で除した $C N R$ の值は, $\mathrm{Co}-\mathrm{Ni}-\mathrm{Mn}$ スピネル ディスクおよび比較用 zip 媒体に関して, 关れ光れ 32.2 お 


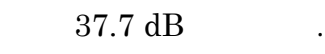

Co-Ni-Mn スピネルディスクおよび比較用 zip 媒体の 5.0-20 MHz における CNRの周波数依存性を Fig. 8 に示す. 5.0-10 MHz においては, 前者の $C N R$ は後者に対して約 5-6 dB 低く, $20 \mathrm{MHz}$ においては約 $12 \mathrm{~dB}$ 低い值であった. $H_{\mathrm{s}}$ か高すぎるのて飽和記録できていない可能性か高いが， $H_{\mathrm{s}}$ の低 減により $C N R$ は改善される可能性がある. 次に, $20 \mathrm{MHz}$ の信号を記録した後の 0-50 MHz 帯域における Co-Ni-Mn スピネルディスクおよび比較用 zip 媒体の $S N R$ を求めたと

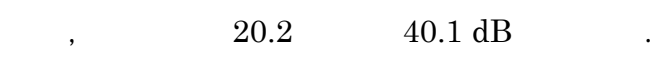

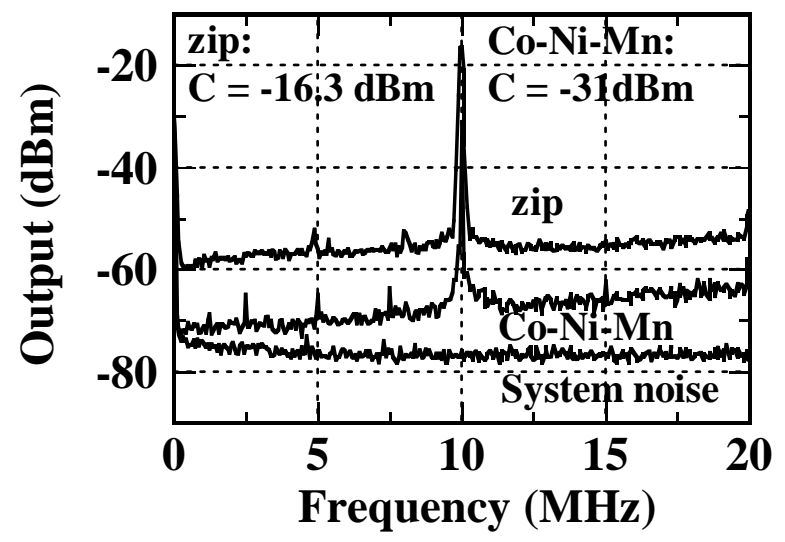

Fig. 7 Signal and noise spectra for $\mathrm{Co}-\mathrm{Ni}-\mathrm{Mn}$ spinel ferrite and zip disks after writing a $10 \mathrm{MHz}$ signal.

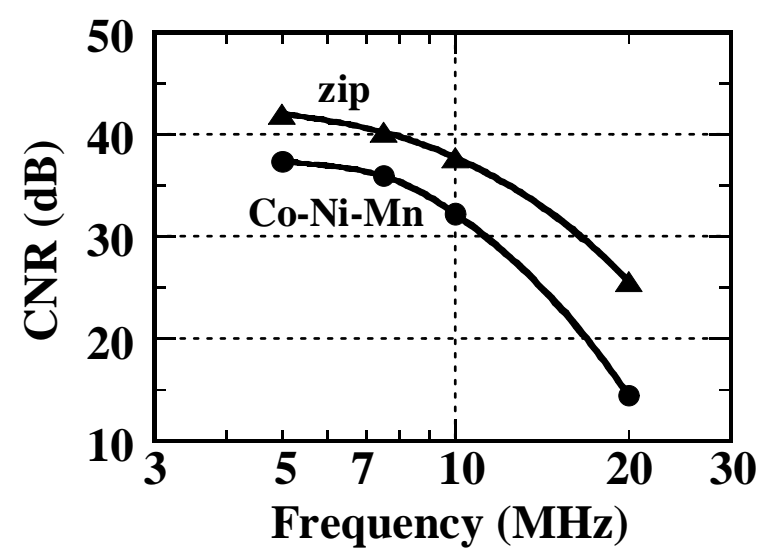

Fig. 8 Frequency dependence of the carrier-to-noise ratio for $\mathrm{Co}^{-\mathrm{Ni}}-\mathrm{Mn}$ spinel ferrite and zip disks.

\section{4. まとめ}

Co-Ni-Mn スピネルフェライト微粒子を用いて作製した ディスクの記録再生の可能性を確認するために, zip ヘッ ドを用いたスピンスタンドにより線記録密度特性, オーバ ーライト特性および信号と雑音の比に関して市販の zip 媒 体と概略を比較した結果, 記録周波数が $20 \mathrm{MHz}$ 以内にお いては, Co-Ni-Mn スピネルディスクの出力は zip 媒体に 対して約 10-13 dB 低いが, 記録再生が可能であることが 初めて明らかになった. 再生出力が低い主な理由として, zip 媒体に比べて $B_{\mathrm{r}}$ が $1 / 3$ で小さいこと, $H_{\mathrm{c}}$ 喲 2 倍て大きい
ことおよび $H_{\mathrm{s}}$ か高いために zip ヘッドで十分に記録できない 可能性か洘えられる. スピネルフェライト微粒子としては, 平均粒径が約 $15 \mathrm{~nm}$ 以下で均一な微粒子の作製, 超常磁性 に近い特に微細な粒子の除去および組成系の探索などによ り, $B_{\mathrm{r}}$ の改善, ヘッドに見合った $H_{\mathrm{c}}$ の選択および $H_{\mathrm{s}}$ の低減など が今後の課題である. 以下に本研究で得られた主な結果を示 す.

(1) Co-Ni-Mn スピネルフェライト微粒子を用いて作製し たディスクおよび比較用 zip 媒体の出力半減線記録密度

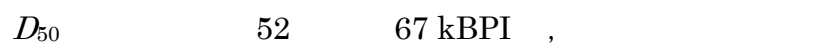
兴れ光れ 55 および $342 \mu \mathrm{V}_{\mathrm{p}-\mathrm{p}}$ であった.

（2） Co-Ni-Mn スピネルフェライト微粒子を用いて作製し たディスクにおいて，低い記録周波 $(1.0 \mathrm{MHz})$ で $L F$ と $R-L F$ の周波数の比が小さい場合は, 比較的良好なオーバー ライト特性が得られた。

（3） Co-Ni-Mn スピネルフェライト微粒子を用いて作製し たディスクおよび比較用 zip 媒体の $10 \mathrm{MHz}$ における $C N R$

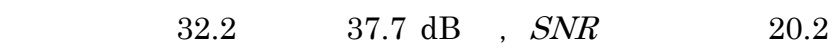
および $40.1 \mathrm{~dB}$ であった.

謝辞 本研究に関して終始ご支援頂き，さらに zip ヘッド および潤滑剂を提供いただいた TDK(蛈)千曲川第一テクニ カルセンター青山 勉主任技師および添野佳一主任技師に 深謝致します．また， Co-Ni-Mn スピネルフェライト微粒 子を作製いただいた戶田工業(㑣)創造本部片元＼cjkstart勉部長に感 謝致します．スピンスタンドをお借りした協同電子システ 么侏記録機器事業部染欲峰男事業部長および営業部佐々木敏 郎次長に感謝の意を表します.さらに，媒体の表面観察に ご協力いただいた(㚘)東陽テクニカ落合達四郎技術顧問およ び分析システム部金丸博美係長に感謝致します.

\section{References}

1) N. Abe, K. Ejiri, and K. Hanai : J. Magn. Soc. Jpn., 26, 1090 (2002).

2) M. P. Sharrock : IEEE Trans. Magn., 36, 2420 (2000).

3) D. J. Sleiter and M. P. Sharrock : IEEE Trans. Magn., 36, 2413 (2004).

4) H. Nishio, Y. Ota, M. Maekawa, and H. Yamamoto : J. Magn. Magn. Mater. 287, 234 (2005).

5) H. Nishio and H. Yamamoto : IEEE Trans. Magn., 41, 3232 (2005).

6) Y. Sasaki, S. Tsuboi, N. Kasajima, S. Kitahata, and M. Kishimoto: IEEE Trans. Magn., 37, 2204 (2001).

7) T. Suzuki and T. Tanaka : IEICE Trans. Electron., E84-C, 1147 (2001).

8) H. Yamamoto, H. Nishio, and N. Yoshida : J. Magn. Soc. Jpn., 29, 269 (2005).

9) M. Kiyama : J. Jpn., Soc. Powder and Powder Metallurgy, 23, 77 (1976).

10) H. Yamamoto, H. Nishio, and N. Wakamura : J. Jpn., Soc. Powder and Powder Metallurgy, 50, 870 (2003).

11) S. Kaneko: Challenge of zip, p. 67 (Ohmsha Ltd. Tokyo, 1999) (in Japanese).

12) JIS B0601-1994, Surface roughness-Definitions and designation, (1994).

2005年 9月 8 日受理 , 2005年10月25日再受理 , 2005年12月16日採録 